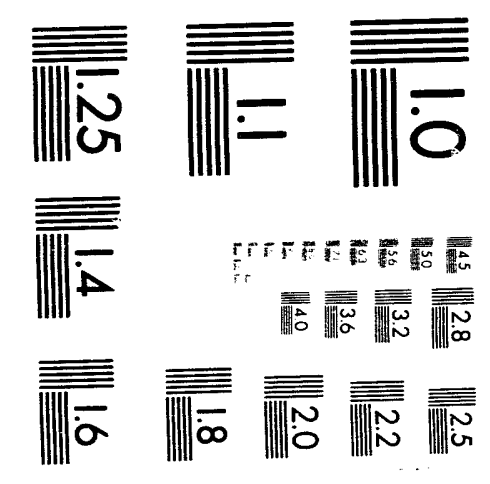



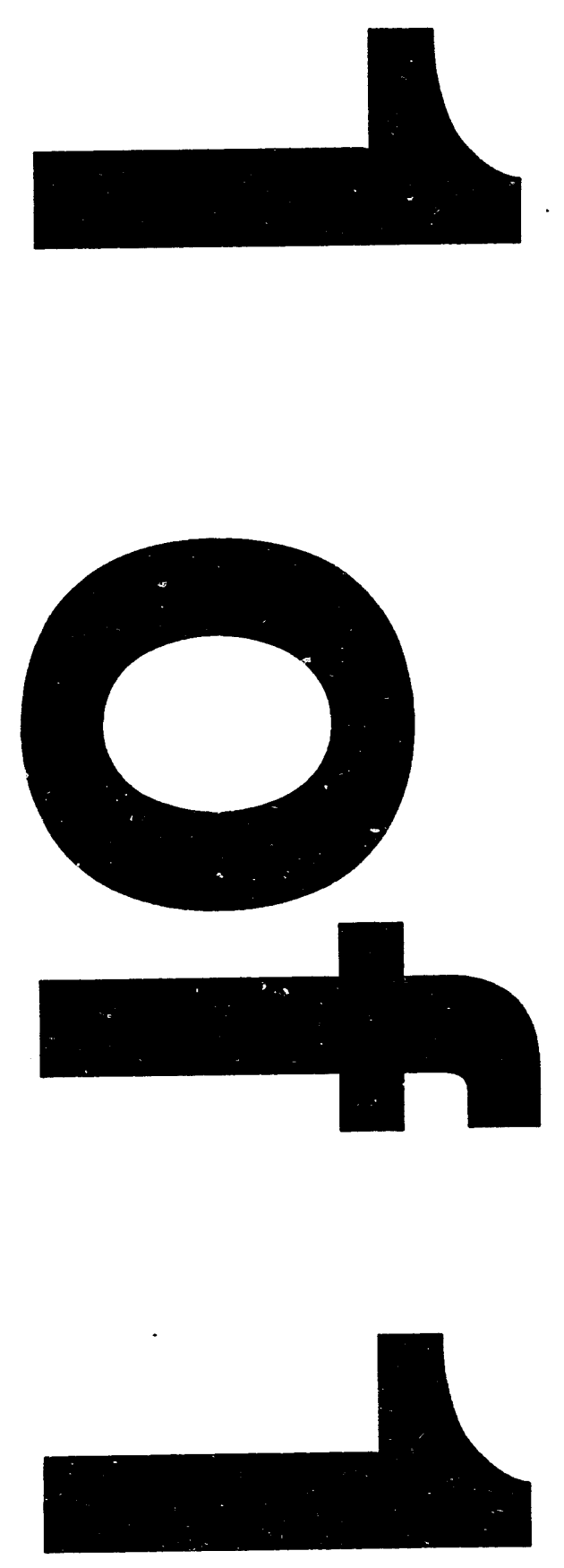


\title{
Selection and Characterization of Lead Alloys for Use in the SDC EM Calorimeter
}

\author{
James Nasiatka \\ High Energy Physics Division \\ Argonne National Laboratory, Argonne, Illinois
}

Lead, because of it's density and ductility, has been used by man for centuries for many things ranging from building materials, to piping; from electrical connections, to radiation shielding, and batteries. However, despite it's extensive and varied use, not much is really known about it's exact physical and structural properties except in a very rudimentary way. The SDC cast lead EM Calorimeter needs to take full advantage of all the properties that the lead alloy has to offer. Hence, a very thorough and detailed understanding of the properties of the lead-absorber structure must be obtained and controlled, so that the integrity of the calorimeter is not compromised. This paper will attempt to detail a series of ongoing experiments used to characterize and define the properties of the Calcium-Tin-Lead alloys for use in the SDC cast lead electromagnetic calorimeter.

\section{Alloy Selection:}

From a mechanical viewpoint, in order for the calorimeter to function correctly, the absorber structure must have a yield strength great enough to withstand the internal stress' developed on the calorimeter assembly, and enough creep resistance to 
resist flowing over the life of the calorimeter. For physics and safety reasons any alloys used must have a very low rate of neutron absorption/activation. The presence of any radioactive isotopes in the lead absorber structure would cause a great deal of problems with the calibration and operation of the calorimeter. In addition, they would pose a potential radiation exposure problem to people working on and maintaining the calorimeter. It would also cause the lead, already a toxic substance in itself, to be classified as a mixed waste, further complicating handling, shipping, and eventually disposal of it.

The alloys initially considered for evaluation were: UNS \#L-50050 - Grade A Lead (99.90\% Pb), \#L-52901 - 4\% Antimonial Lead (96\% Pb, 4\% Sb), \#L-53105 - 6\% Antimonial Lead (94\% Pb, 6\% Sb), Tellurium Lead (.05\% Te), \#L-50737 - Battery Grid Alloy $(99.4 \% \mathrm{~Pb}, .065 \% \mathrm{Ca}, .50 \% \mathrm{Sn})$, and \#L-50750 - Battery Grid alloy ( $98.6 \% \mathrm{~Pb}$, $.065 \% \mathrm{Ca}, 1.3 \% \mathrm{Sn})$. The Grade A Lead provided a good control sample, but cannot be used in the calorimeter because of it's low yield strength and susceptibility to creep effects at low temperatures. The other alloys were chosen based on various vendor recommendations for strength, creep resistance, and ease of casting.

The Tellurium and Antimonial leads were almost immediately discarded because of the high percentages of neutron absorption/activation that they exhibit. The calcium-tin alloys (\#L-50737 \& \#L-50750) are standárd, commernally available alloys commonly used for the fabrication of plates inside of leac' zcir' autcmobile batteries. They were initially selected because they werr "is: ocily comirnurcially available, but have superior yield strengths and creep resistarici sval pure lead, and have only additives that exhibit low levels of neutron absorption.

\section{Mechanical Testing:}

Since published data on the properties of these lead alloys was very scarce, a series of mechanical tests were performed to establish those properties, and verify 
what work has already been done.

One of the problems with casting $\mathrm{Ca}-\mathrm{Sn}-\mathrm{Pb}$ is that the calcium tends to not only float to the top, but also oxidizes out of the mixture. This problem limits the available time for casting to approximately 30-45 minutes after the lead is molten. Having an inert gas (nitrogen) as the atmosphere over the melt decreases the oxidation rate, allowing more pouring time. As a check on our casting technique, we decided to examine the distribution of the calcium in the mixture after casting. The calcium in the mixture acts as a hardening agent, and gives an initial added strength to the lead. If the calcium has time to float out, the material hardness will vary with height throughout the castings.

The third SDC 18-cell casting was made using \#L-50737. One tower was cut out of the structure, and a 3 in. wide strip was cut from each of the six layers. Three hardness readings were taken for each layer across the width of the sample at six points along the height. These readings were taken using the Rockwell $F$ scale (for very soft materials), on a Kentroll model CT-2 hardness tester. As can be seen in Fig. 1 , the lead is softest at the top and bottom, and ranges from $R_{f} 70-R_{f} 94$. The average hardness is about $R_{f} 83.3$, which is $79-80$ on the Brinell scale $(10 \mathrm{~mm}$ ball/ $/ 500 \mathrm{Kg}$ load). The distribution is fairly even, indicating that the calcium is distributed throughout the casting, and that it is properly mixed.

\section{Tensile Testing:}

A set of tensile tests were conducted to physically determine the mechanical properties of the calcium-tin lead alloys. We are specifically interested in the value of Young's Modulus $(E)$ and the Yield Stress of the material.

To accomplish this, a series of $1^{\prime \prime}$ wide $\times 1 / 4^{n}$ thick $\times 12^{n}$ long lead strips of each alloy were cast, and then a $.375^{\prime \prime} \times 2.00$ " long test area was machined out (as per ASTM standards.) The test samples were then loaded using a Tinius Olsen 20,000\# 
Electromatic Testing machine. To accurately record the data the system was set up to digitally record data by attaching a Kinetic Systems CAMAC Crate and Multiplexer to a $P C$ and the strip chart recorder.

Rather than try to read the output of the sensors directly, and have to worry about gain and calibration across the different load and distance ranges, the electric signals which drive the $x$ and $y$ (force and distance) axis of the recorder from $0-100 \%$ of range were sampled. This allows the force and distance scales to be set in the normal manner, and the recorded data is scaled correspondingly during processing. As a check of the accuracy of the recording process, the first samples were also plotted simultaneously on the chart recorder, and then compared to the digital data. They were found to match exactly.

To assist in determining the easiest and best method of casting, the samples were cast at various temperatures, and with both the standard graphite based lubricant we have been using as a mold release, and a much less messy and environmentally damaging silicone based release. These changes were found to have no noticeable effect on the strength of the casting. Variations in cooling rates, and the casting temperature did result in varying surface finishes.

For each sample tested, a force - distance curve was obtained, and then converted into stress vs strain. The yield stress was visually determined from this plot. A simple linear regression was done on the "straight line" elastic yield portion of the stress - strain curve to determine Young's Modulus. To confirm the regressions accuracy, $95 \%$ confidence bars were calculated and plotted with the curve. These show that the regression matches the data very well. The average yield stress and Young's Modulus were determined simply by averaging over the samples taken.

Results for the tests are shown in Figs. 3 and 4. For alloy \#L-50737, the average yield stress is between 3,200 and 3,500 psi. The average value for Young's Modulus is $3.05 \times 10^{6} \mathrm{psi}$. Alloy \#L50750 shows an average yield stress of 5,500 - 
6,000 psi, and has an average Young's Modulus of $5.36 \times 10^{6} \mathrm{psi}$. An additional series of test castings are being evaluated for confirmation of these numbers, and will be released as soon as they are done.

\section{Creep Testing:}

Creep strain and fracture are the result of time and temperature dependent deformations which occur when materials are subjected to stress. All metals are susceptible to creep effects, but they are only noticeable over long periods of time, or at temperatures approaching the materials melting point. Since lead has a relatively low melting point (about $320^{\circ} \mathrm{C}$ ), room temperature is sufficiently elevated to cause creep effects to be noticeable over the life of the calorimeter. To be effective, the alloy used in the EM section must resist creep at an average temperature of $80^{\circ} \mathrm{F}\left(27^{\circ} \mathrm{C}\right)$ - an average summer day around the Dallas area - for the effective life of the calorimeter, approximately 10 years $(87,600$ hours $)$.

Since it is impractical to run the test for the entire ten years, the effects of creep were accelerated by using the Larson-Miller time-temperature relationships (Transactions of the ASME, Volume 74, 1952 - "A Time-Temperature Relationship for Rupture and Creep Stresses"). This relationship is described by the equation:

$$
T_{1}\left(C+\log \left(t_{1}\right)\right)=T_{2}\left(C+\log \left(t_{2}\right)\right)
$$

where $T_{1}$ is the desired temperature, $T_{2}$ is the iemperature at which the measurements are made, $t_{1}$ and $t_{2}$ are the respective times, and $C$ is a material constant. The equation itself is considered a standard for comparison, however, the value of $C$ varies for different materials. Larson and Miller experimentally determined the value of $C$ for many different materials (not including lead, though), and found them to generally range from 18 to 23 . They decided that for most practical purposes, a value of 20 , 
while not exact, was satisfactory for most calculation purposes. Since no data on the value of $C$ for lead alloys has been found, $C$ is assumed to be 20 until enough timetemperature tests can be performed to determine it's exact value. Using a value of $C=$ 20 , it is possible, by increasing the temperature to around $127^{\circ} \mathrm{F}\left(58^{\circ} \mathrm{C}\right)$, to be able to simulate 100,000 hours (11.4 years) in 41 days.

An initial series of tests were conducted using samples that were hung from a unistrut frame in a small oven, using dial indicators to measure the elongation. First, to establish a reference, a set of $1.00^{\prime \prime} \times 6.00^{\prime \prime} \times 3 / 32^{n}$ pure lead strips were hung with weights applying stress levels of $40,50,60$, and 80 psi. These were allowed to hang for 1961 hours at $127^{\circ} \mathrm{F}$, which simulated 24 years at $80^{\circ} \mathrm{F}$ (Fig. 5). This results in a strain rate of $1.04 \times 10^{-4} \mathrm{in} / \mathrm{in} / \mathrm{year}$, or about $100 \mathrm{micro}-\mathrm{strain} / \mathrm{year}$ for the $80 \mathrm{psi}$ samples. Two samples cut from the SDC 18-cell test casting were also hung in the same oven under 80 psi loading for 700 hours (7.75 years), and showed a strain rate of 5.19 $\times 10^{-5} \mathrm{in} / \mathrm{in} /$ year (Fig. 6). This is about a factor of two better than the pure lead specimen. Additionally, two specimens of the \#L-50750 alloy that were work hardened for Lawrence Berkeley Laboratory were placed under an 80 psi load for 960 hours (12 years), and showed a strain rate of about $4.17 \times 10^{-5} \mathrm{in} / \mathrm{in} /$ year (Fig. 7).

Another series of accelerated time creep tests were performed using samples of the \#L50737 alloy that were fabricated for additional tensile testing. These samples had high-elongation strain gauges attached to them, and were suspended from a unistrut frame that was placed in an oven at $130^{\circ} \mathrm{F}\left(54.5^{\circ} \mathrm{C}\right)$. A total of eight samples were loaded with 1, 2, 3, and 4 lead bricks to load them at 320 psi, 586 psi, 875 psi, and 1173 psi, respectively. An RTD temperature probe (Omega \#RTD-805) was mounted in the oven to check the temperature, and one unstressed sample was in place to compensate for temperature induced strains on the gauges. The gauges and RTD were read out using a Micro Measurements System 4000 strain gauge scanner coupled to a $486 / 33$ PC clone. 
Initially, tests of the clamping system were made to ensure that the weights would not fall off of the samples. A single strip was used to hold 137\#, which induced a stress of 1,100 psi for 72 hours at room temperature, and showed no measurable elongation.

Results for the accelerated time creep test shows that all samples above 586 psi failed, and that the 875 psi samples would last between 9 and 15 years. The 1173 psi samples would last 3-4 years at most. However, the 320 psi and 586 psi samples did not fail after 30.4 years of simulated time. A time-temperature correlation is crudely shown during the times from 25-35 hours, when the oven was inadvertently shut off, and at 825 hours where necessary maintenance of the electrical system required the oven to not be run continuously. During these times, when the temperature dropped, the corresponding creep rates dropped proportionally as well. For the 320 psi samples, the total elongation was $.003^{\prime \prime}$ for a $1^{\prime \prime}$ sample which corresponds to $9.8 \times 10^{-5}$ in/in/year or about 100 micro-strain/year (Fig. 8). This is the same value that was determined for pure lead at 80 psi, showing that the \#L50737 alloy is about 4 times more resistant to creep than pure lead. To precisely determine the value of $\mathrm{C}$ for the \#L50737 alloy, additional creep testing at different temperatures is planned, so that a correlation can be developed.

\begin{tabular}{|c|c|}
\hline Sample & Elongation \\
\hline Pure Pb at 80 psi & $1.04 \times 10^{-4} \mathrm{in} / \mathrm{in} /$ year \\
\hline 18 Cell Casting at 80 psi & $5.19 \times 10^{-5} \mathrm{in} / \mathrm{in} /$ year \\
\hline Work Hardened LBL Alloy (\#L50750) & $4.17 \times 10^{-5} \mathrm{in} / \mathrm{in} /$ year \\
\hline \#L50737 Alloy at 320 psi & $9.86 \times 10^{-5} \mathrm{in} / \mathrm{in} /$ year \\
\hline
\end{tabular}




\section{Chemical Anaiysis:}

Understanding and controlling the composition of the alloys is extremely important for a variety of reasons. The amount of calcium and tin in the mixture controls not only the mechanical strength and creep resistance, but also determines the ease with which it can be cast. The Ca-Sn lead used for testing and development of the SDC prototype calorimeters was obtained from two separate sources. Tensile and creep test samples were cast by Quick Cable Corp. of Racine, Wisconsin who obtained the refined alloy from Tonolli Canada (Ontario, Canada). Calorimeter test castings were poured at Terra Corp. of St. Louis, Missouri who mixed the alloy in-house. To confirm the chemical composition of the castings, samples taken from tensile samples of both alloy \#L-50737 and \#L-57070, the 10-tower mechanical test model, and the first high$\eta$ test casting were sent to the ANL Analytical Chemistry division for analysis of their chemical content. Vendor certification was provided for the tensile samples and the High- $\eta$ casting (Figs. 9 - 11).

Argonne's Analytical Chemistry group used Inductive Coupled Plasma Atomic Energy Spectrum (ICP-AES) analysis to confirm the composition of the samples (Figs. 12-14). All show a calcium level of approximately .06\%, and tin levels of .5\% (1.3\% for \#L-50750), with an accuracy of $\pm 10 \%$.

\section{DISCLAIMER}

\footnotetext{
This report was prepared as an account of work sponsored by an agency of the United States Government. Neither the United States Government nor any agency thureof, nor any of their employees, makes any warranty, express or implied, or assumes any legal liability or responsibility for the accuracy, completeness, or usefulness of any information, apparatus, product, or process disclosed, or represents that its use would not infringe privately owned rights. Reference herein to any specific commercial product, process, or service by trade name, trademark, manufacturer, or otherwise does not necessarily constitute or imply its endorsement, recommendation, or favoring by the United States Government or any agency thereof. The views and opinions of authors expressed herein do not necessarily state or reflect those of the United States Government or any agency thereof.
} 


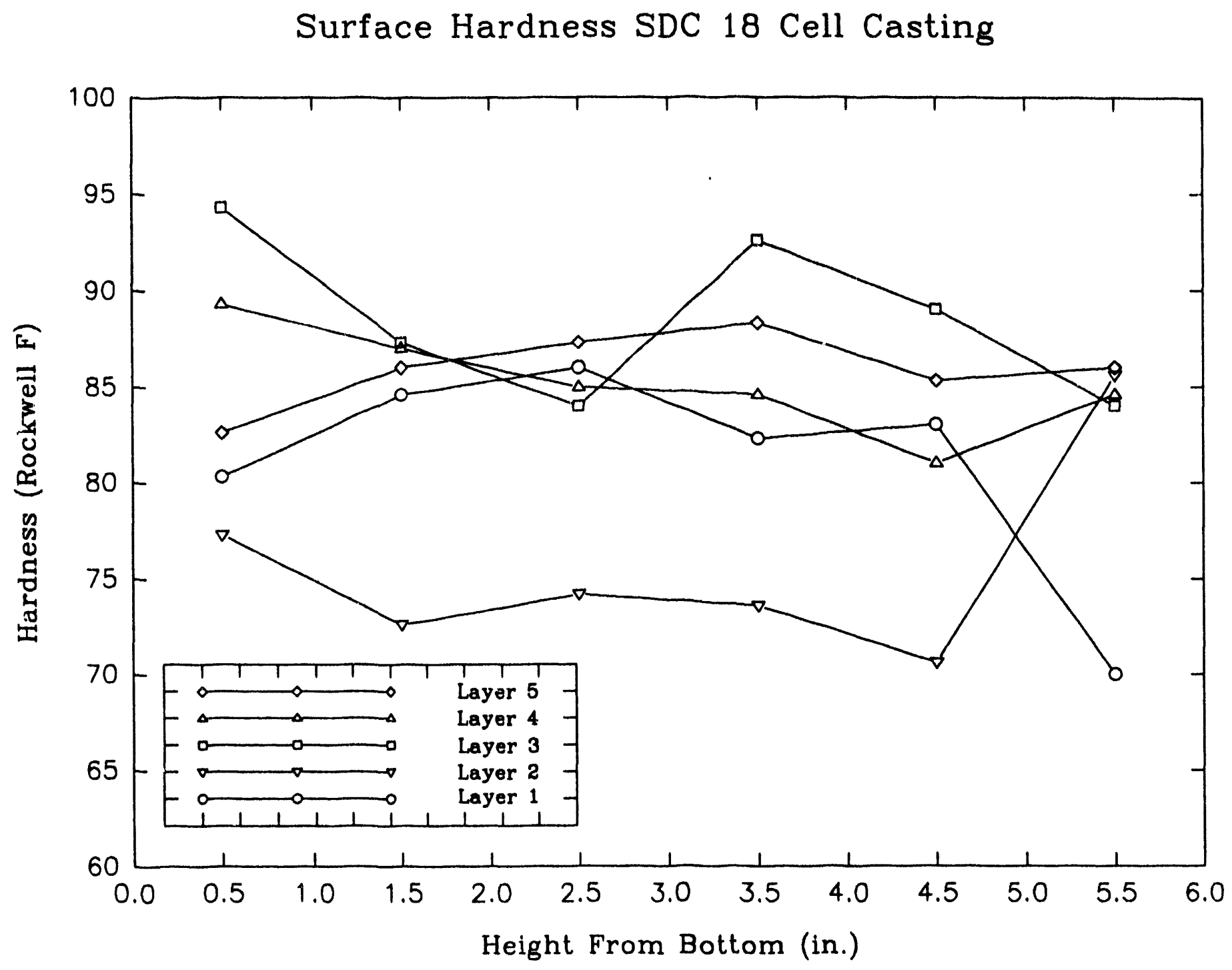

Figure 1 


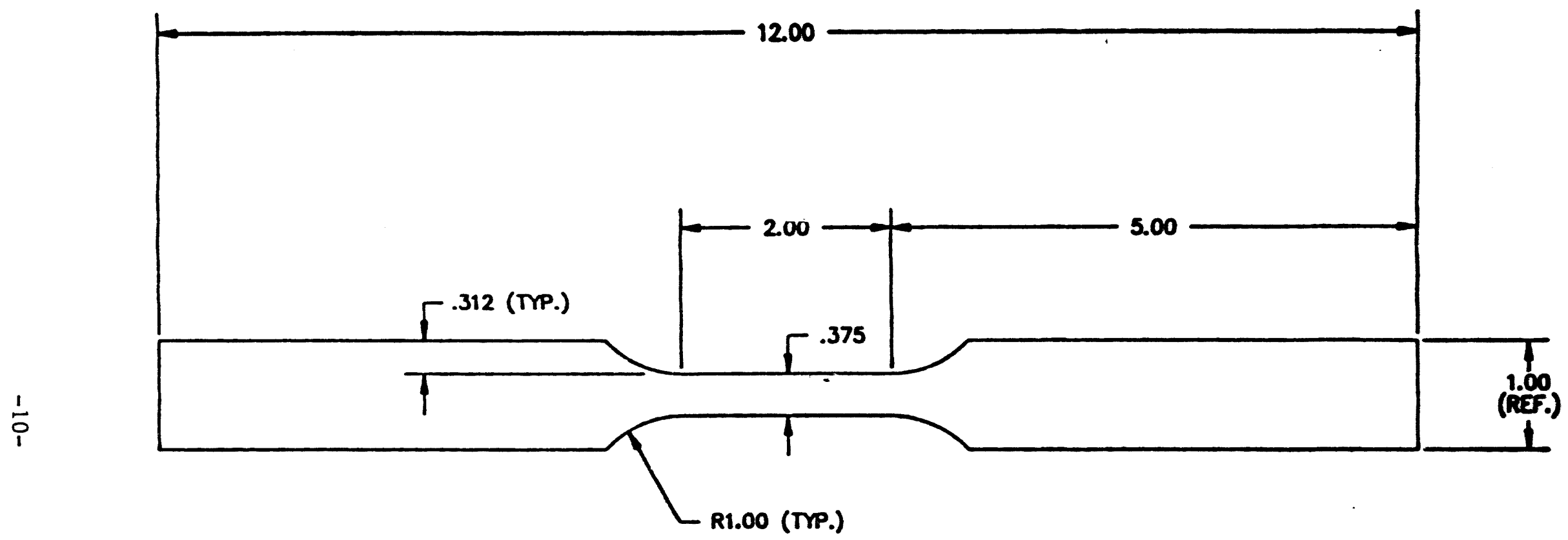

$\underline{\text { TEST STRIP }}$

Figure 2 
Stress - Strain Curves for L50737 Lead Alloy $.06 \% \mathrm{Ca} .5 \% \mathrm{Sn}$

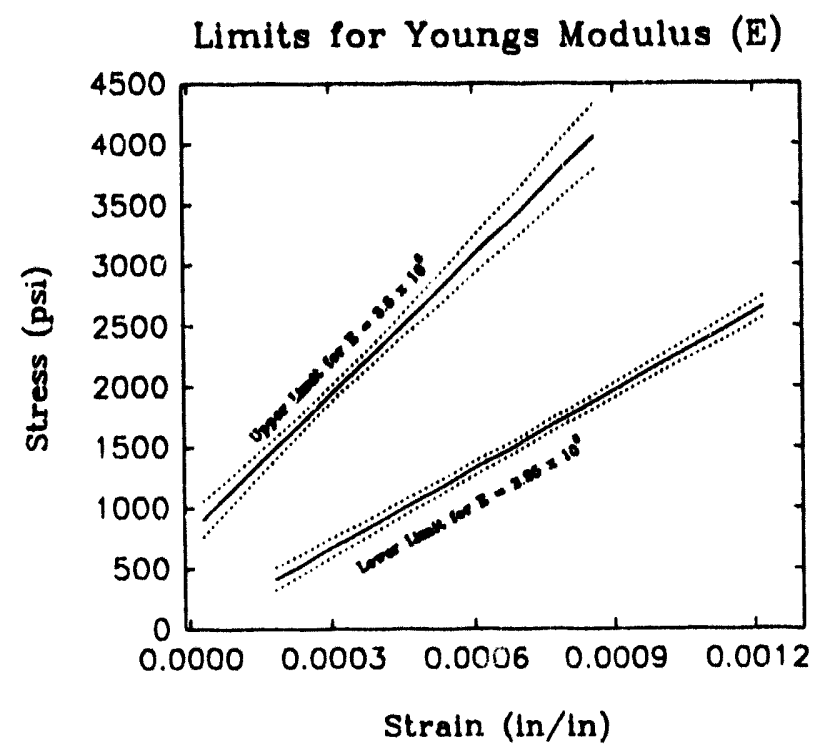

$$
\begin{aligned}
& \sigma_{y}=3,200-3,500 \text { p.s.i } \\
& E=3.05 \times 10^{6} \text { p.s.i }
\end{aligned}
$$

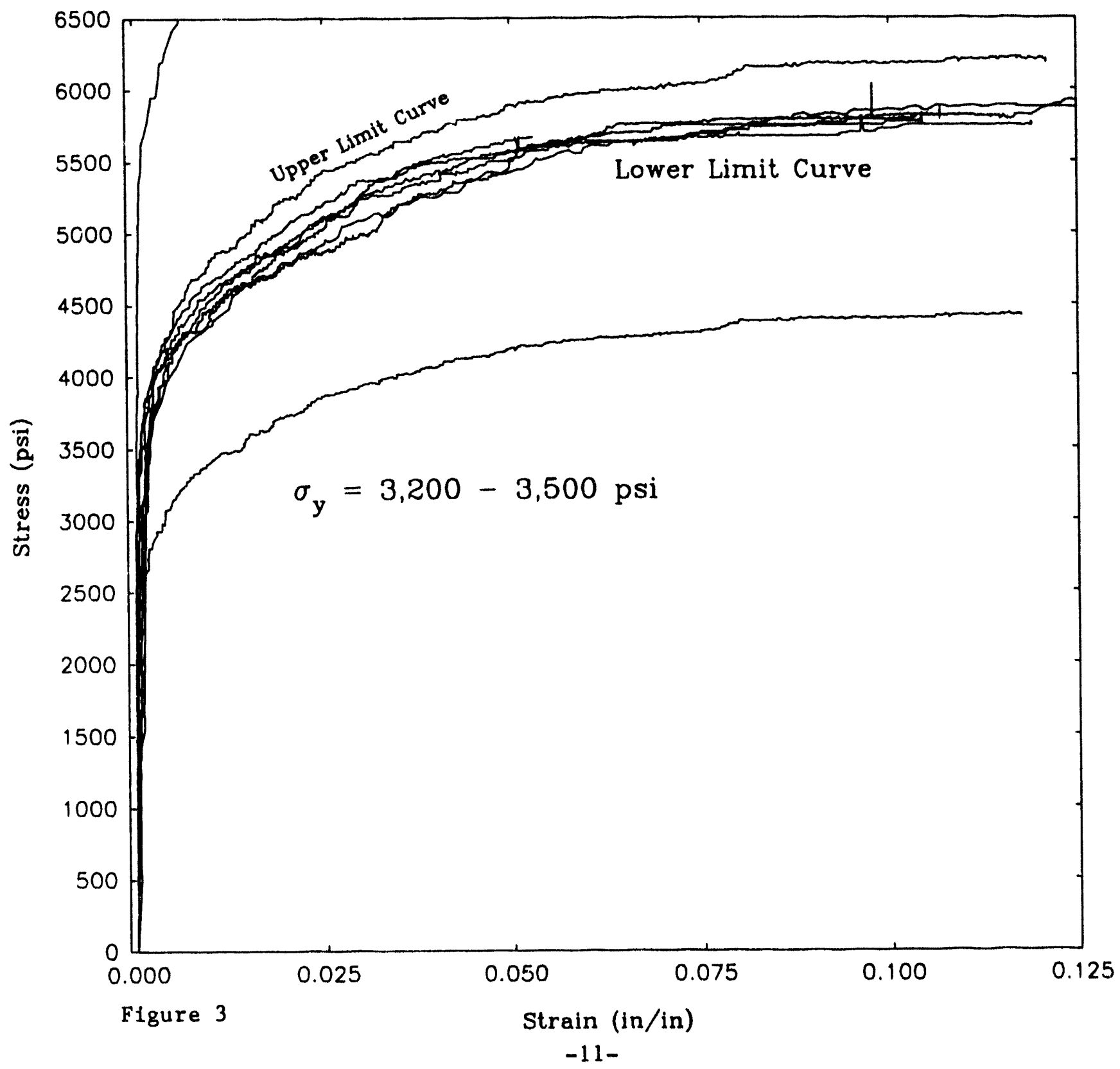




\section{Stress - Strain Curves for L50750 Lead Alloy $0.06 \% \mathrm{Ca} 1.3 \% \mathrm{Sn}$}

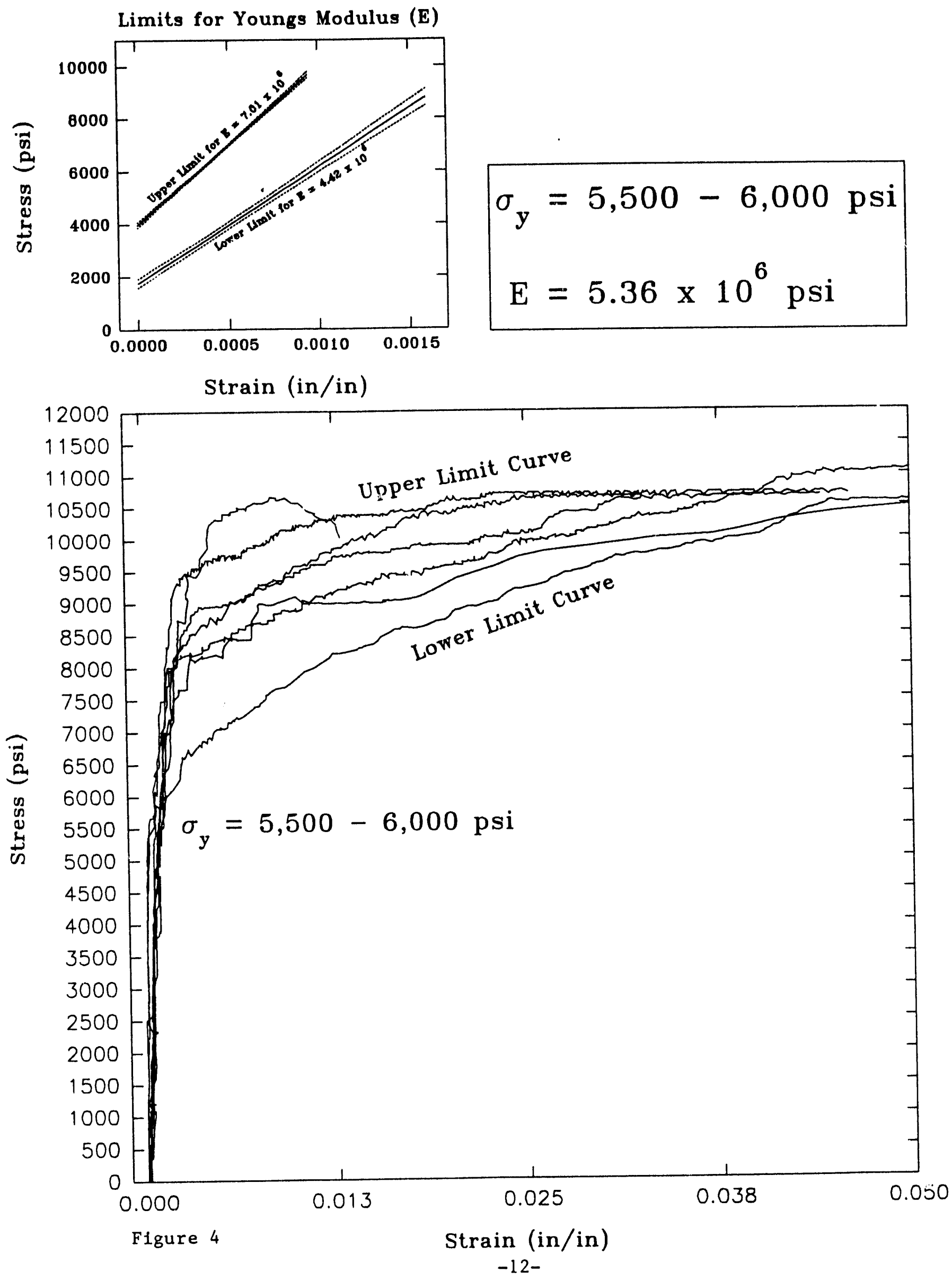




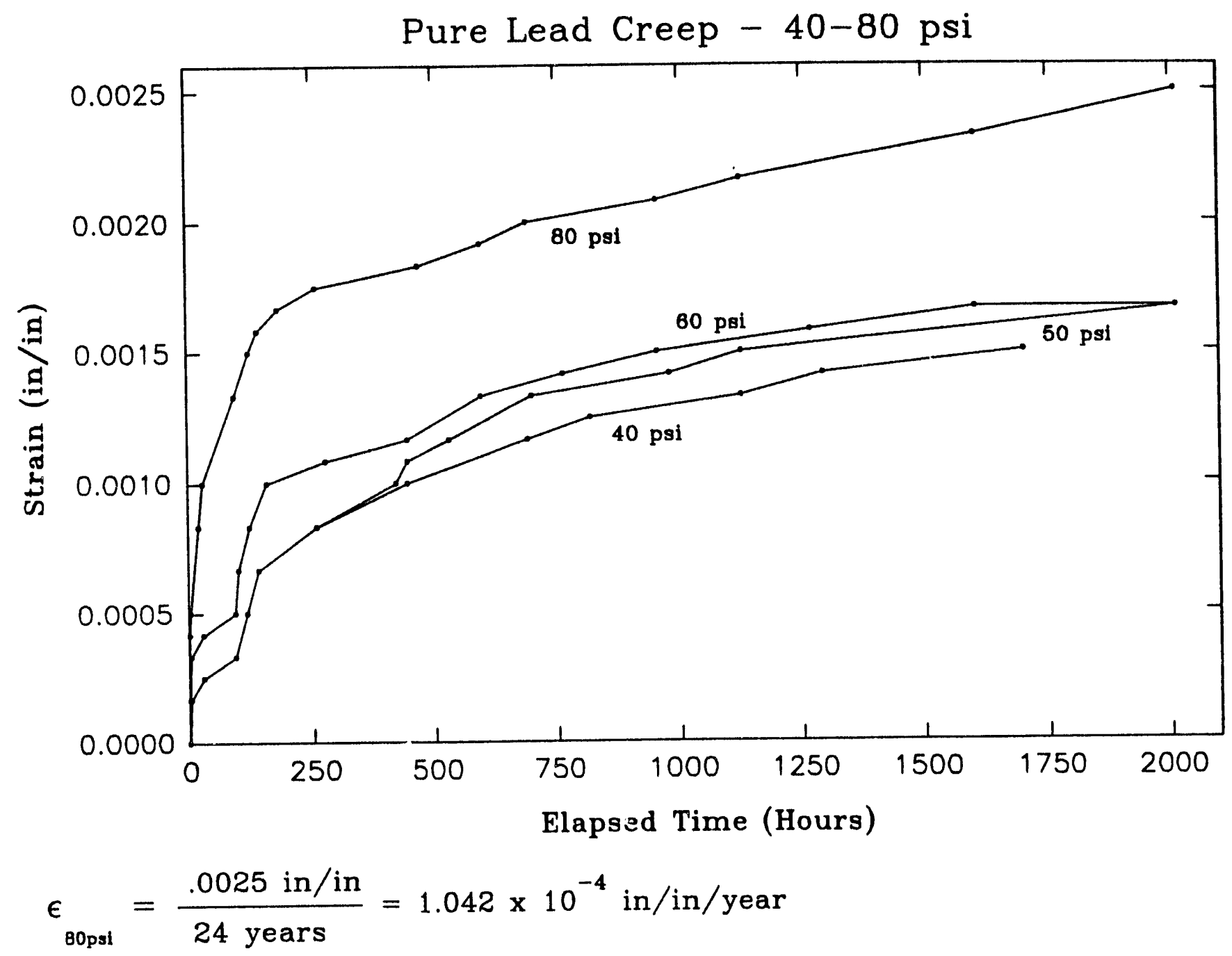

Figure 5 

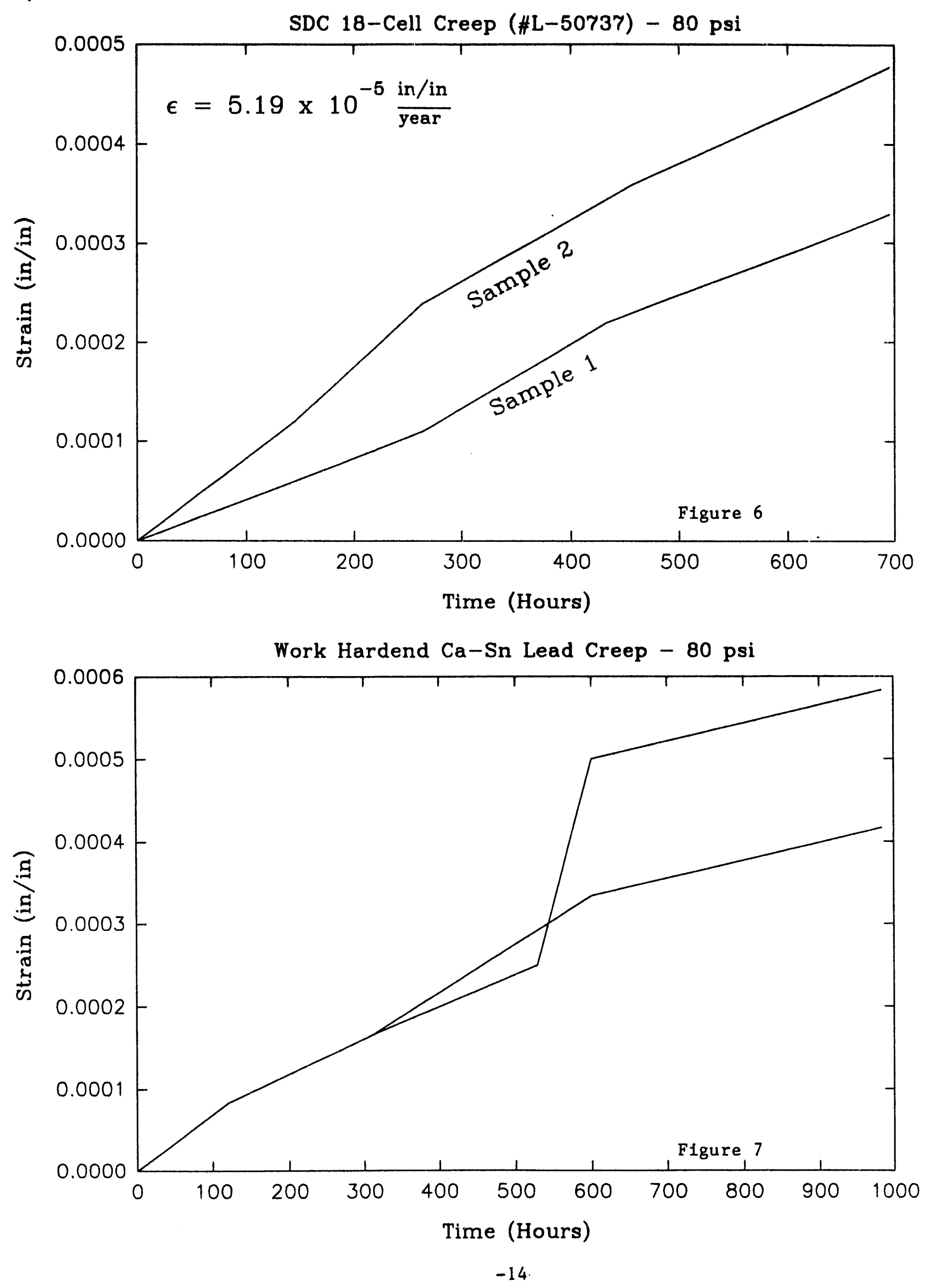


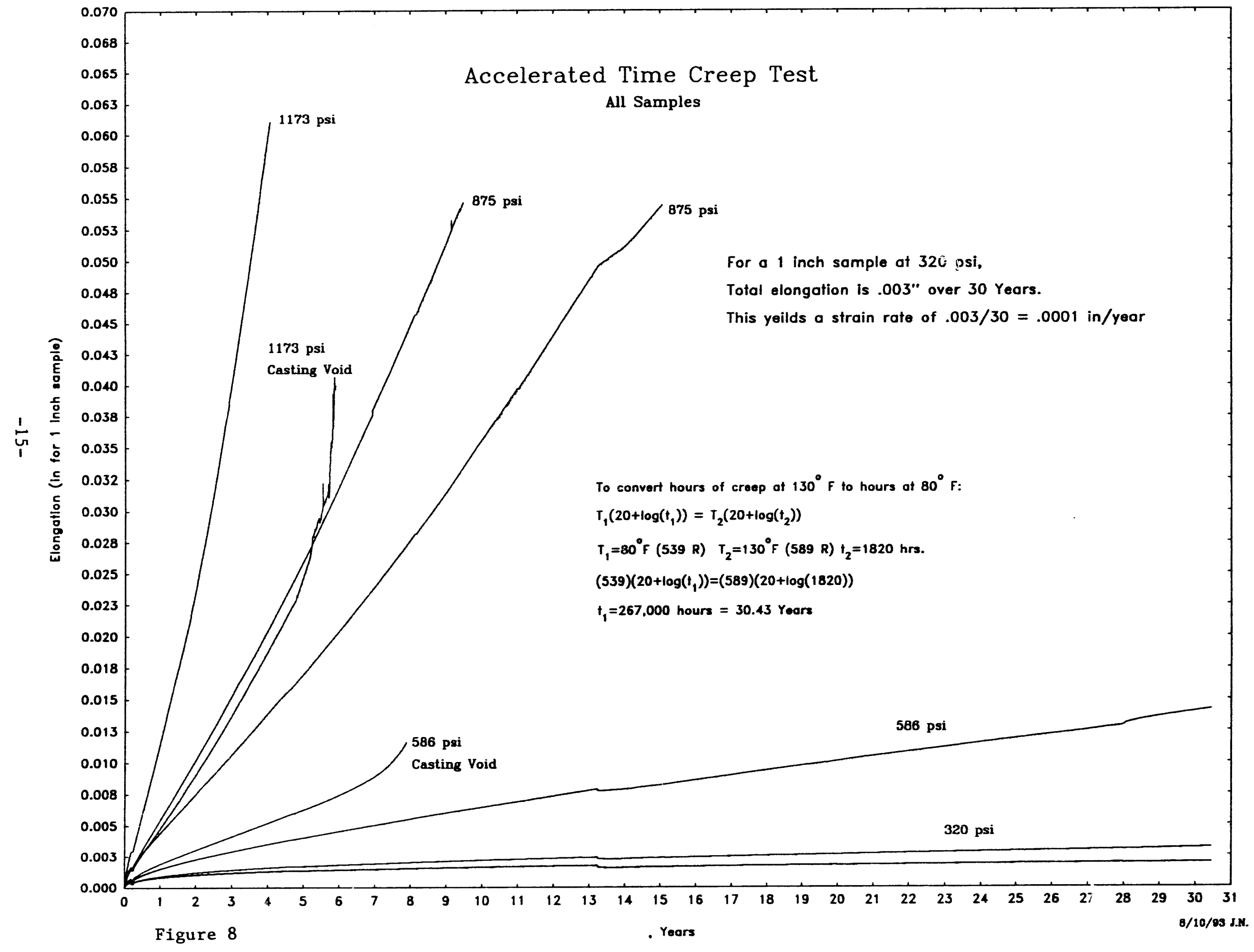




\section{TARACORP INDUBYRIEB, INC. - EOTT PUNAY}

No

9744

Date Received 1/07/93

Dopt. Maxed Motal "B"

sample Calcium head

Marked I-479

Pot Number

\section{CERTIFICATE OF MUAYXIS}

\section{CONTENTS OF METAL}

$\mathrm{Pb}$ Balance

$9 n+.52$

$\mathrm{sb} \quad-.001$

$\mathrm{Cu}$ .001

As $=: 001$

$81 \quad .01$

Ag $\quad .001$

$\mathrm{Ca} \quad .06$

\section{CONTENT8 of METAL 8}

Ni $\quad-.001$

Al

$\ln \quad-.001$

cd $\quad-.001$

s

.0002

$T 0 \quad-.001$

P. -.001

\section{REATRR8}

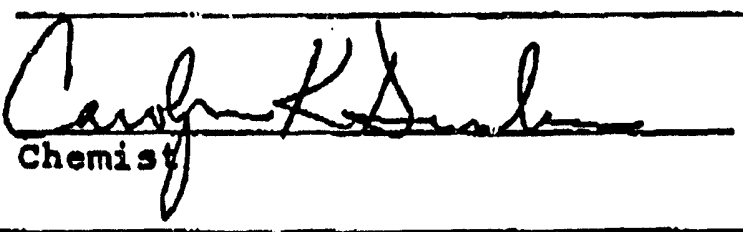

SDC H/:ETA: CASTING III

Figure 9

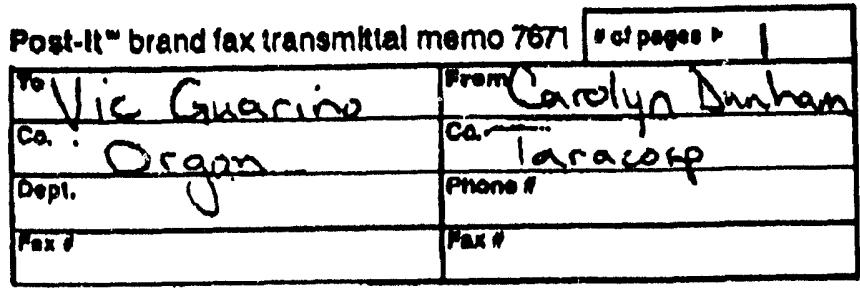


TONOLLI CANADA LTD.

NON-FERROUS METALS REFINEAY 1333 ronou now - Mississauea

ontranio - canina

ur 24

CERTIFICATE OF AMALYSIS

L-5073?

$\Gamma$

QUICK CABTE CORP. 2501 EATON IANE, RACDNE, WI 53404 U.S.A.

\section{7}

Dane Jury 2/92

Customer ordar No.

Our order No.

PRODUCT: Pb/Sn/Ca ' 50737

ELEMENT NO.

ANTIMONY

TIN

ARSENIC

COPPER

BISNUTH

SIIVER

NICKEL

CAICIUM

IRON

ZINC

AIIMINTIM

Figure 10

\begin{tabular}{|c|c|c|}
\hline & \multicolumn{2}{|c|}{ ANALYSIS IN PEACENTAGE OF WEIGHT } \\
\hline Analyeis ". & 1603 & Analysis " \\
\hline Heat " & 346 & Heat. \\
\hline Woight ib. & 4000 & Weight ib. \\
\hline
\end{tabular}

Analrsis

Heat N

Woight lb.

$$
10.0005
$$

0.51

\begin{tabular}{c}
$\frac{\angle 0.0005}{0.0001}$ \\
\hline 0.0097 \\
\hline 0.0021 \\
\hline 0.0001 \\
\hline 0.067 \\
\hline$\angle 0.001$ \\
\hline$\angle 0.001$
\end{tabular}

$\angle 0.001$ 
TONOLLI CANADA LTD.

NON-FERROUS METALS REFINERY

1333 TOMOLH hOND - MissisénUCA

ontanio - cannda

in $2 \mathrm{M}$
Tamon:

(410) emeneses

nase

coesuas

cNive

TONOLUFON TORONTO

CERTIFICATE OF ANALYSIS

Ĺ- 50750

7

Date 0 C.T. $12 / 90$

QUICK CABLE CORP.

2501 EATON IANE,

RACINE, WI 53404

U.S.A.

L

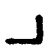

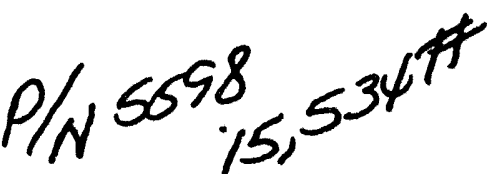

Customer order No.

our order No. P. $0 . \$ 2926$

PROOUCT: $\mathrm{Pb} / \mathrm{Sn} / \mathrm{CA}$

ELEMENT NO.

ANTIMONY

TIN

ARSENIC

COPPER

BISMUTH

SILVER

NICTOM

CALCIUM

IRON

2INC

Analysis N $\frac{0682}{264}$

Analysis *

Heat $A$

Woight 16.

\begin{tabular}{l}
\hline$\angle 0.0005$ \\
\hline 1.31 \\
\hline$\angle 0.0005$ \\
\hline 0.0001 \\
\hline 0.0098 \\
\hline 0.0038 \\
\hline$\angle 0.0001$ \\
\hline 0.066 \\
\hline$\angle 0.001$ \\
\hline$\angle 0.001$ \\
\hline
\end{tabular}

Analysis "

Heat "

Woight ib.

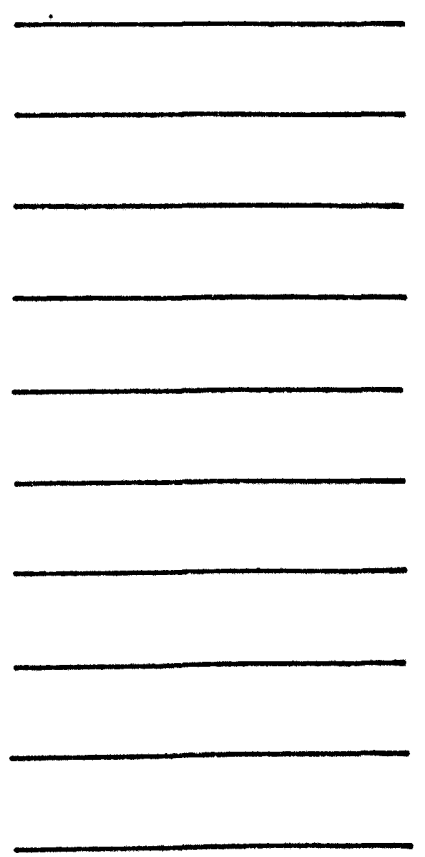

Figure 11 


\begin{tabular}{|c|c|c|c|c|c|c|c|c|c|c|c|c|c|c|c|c|c|c|c|c|}
\hline Our No. & Your No. & Material & Ao & AI & As & B & $8 a$ & Be & 81 & $\mathrm{Ca}$ & Co & $C r$ & $\mathrm{Cu}$ & Fo & $\mathrm{HO}_{\mathrm{O}}$ & $\mathbf{K}$ & LI & $c d$ & Se & \\
\hline $0,52-01$ & Hand & fbela & & 5.02 & <.05 & & R.012 & r.001 & & 0259 & S.1B & 5,002 & 6.102 & S.006 & & & & R.002 & 6.05 & \\
\hline gians & 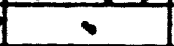 & -2 & & $\sim$ & & & $\infty$ & $\infty$ & & 0.051 & - & $\infty$ & - & - & & & & $\sigma$ & & \\
\hline$a$ & bsdeces & $=$ & & 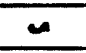 & 5.06 & & $=$ & $n$ & & 2050 & 5 & $n$ & 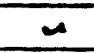 & 4 & & & & $\infty$ & K.05 & \\
\hline Band & $\infty$ & $=$ & & $\cdots$ & & & 1 & $\omega$ & & 0.050 & $=$ & - & 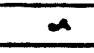 & - & & & & $n$ & & \\
\hline$a$ & 237 F2 & 8 & & 4 & 6.15 & & - & - & & 0.059 & 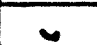 & $\omega$ & $m$ & - & & & & $n$ & K.05 & \\
\hline onn- & - & $=$ & & $\infty$ & & & - & - & & 0,058 & $\omega$ & - & - & - & & & & $n$ & & \\
\hline & & & & & & & & & & & & & & & & & & & & \\
\hline sece & & & & & & & & & & & & & & & & & & & & \\
\hline$-x=y$ & & & & & & & & & & & & & & & & & & & & \\
\hline & & & & & & & & & & & & & & & & & & & & \\
\hline
\end{tabular}

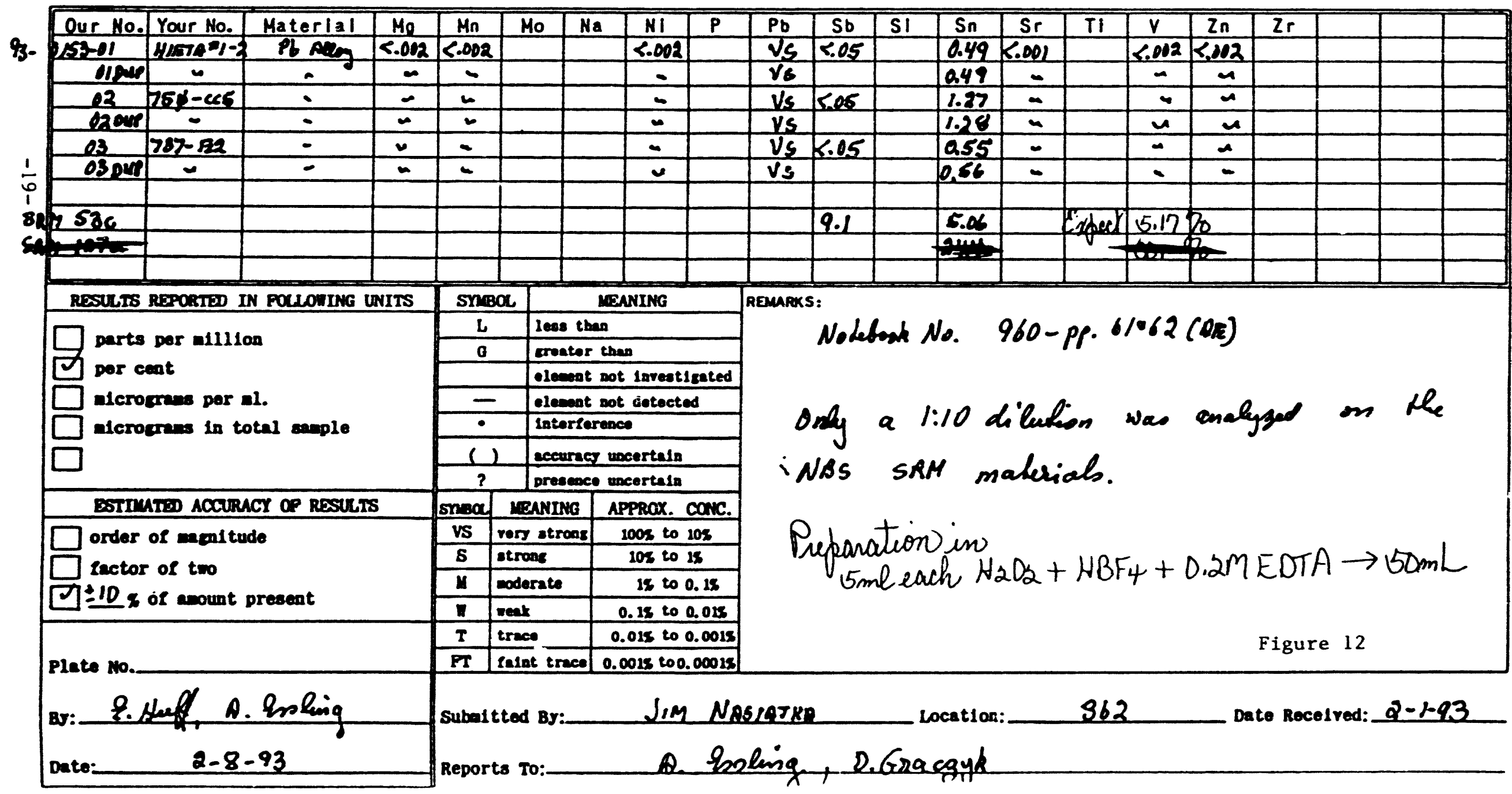


ICP-SPECTROCHEMICAL ANALYSIS REPORT (Supplement)

SPEC NO. 57233

\begin{tabular}{|c|c|c|c|c|c|c|c|c|c|c|c|c|c|c|c|c|c|c|c|c|}
\hline Our No. & Your No. & Materlal & $A_{0}$ & AI & As & 8 & $8 \mathbf{a}$ & $8 e$ & 81 & $\mathrm{Ca}$ & Co & $\mathrm{Cr}$ & $\mathrm{Cu}$ & Fe & $\mathrm{Ho}_{0}$ & $K$ & LI & $c d$ & Se & \\
\hline $2 / 53-e 1$ & $\ln ^{2} 3 x^{2} /-2$ & Ph oren & & 5.02 & 5.01 & & 6.002 & $<.001$ & & 0.02 & F.002 & K.002 & 6.002 & K.005 & & & & 2.002 & 5.01 & \\
\hline 12 & 26 -cas & - & & 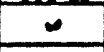 & 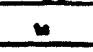 & & \begin{tabular}{|l} 
\\
\end{tabular} & $a$ & & 0,02 & $\infty$ & $1=$ & - & - & & & & - & $\omega$ & \\
\hline 03 & $282-\overline{2} 2$ & - & & - & - & & $\infty$ & $\infty$ & & 6064 & - & - & - & - & & & & - & $n$ & \\
\hline & & & & & & & & & & & & & & & & & & & & \\
\hline & & & & & & & & & & & & & & & & & & & & \\
\hline & & & & & & & & & & & & & & & & & & & & \\
\hline & & & & & & & & & & & & & & & & & & & & \\
\hline & & & & & & & & & & & & & & & & & & & & \\
\hline & & & & & & & & & & & & & & & & & & & & \\
\hline & & & & & & & & & & & & & & & & & & & & \\
\hline
\end{tabular}

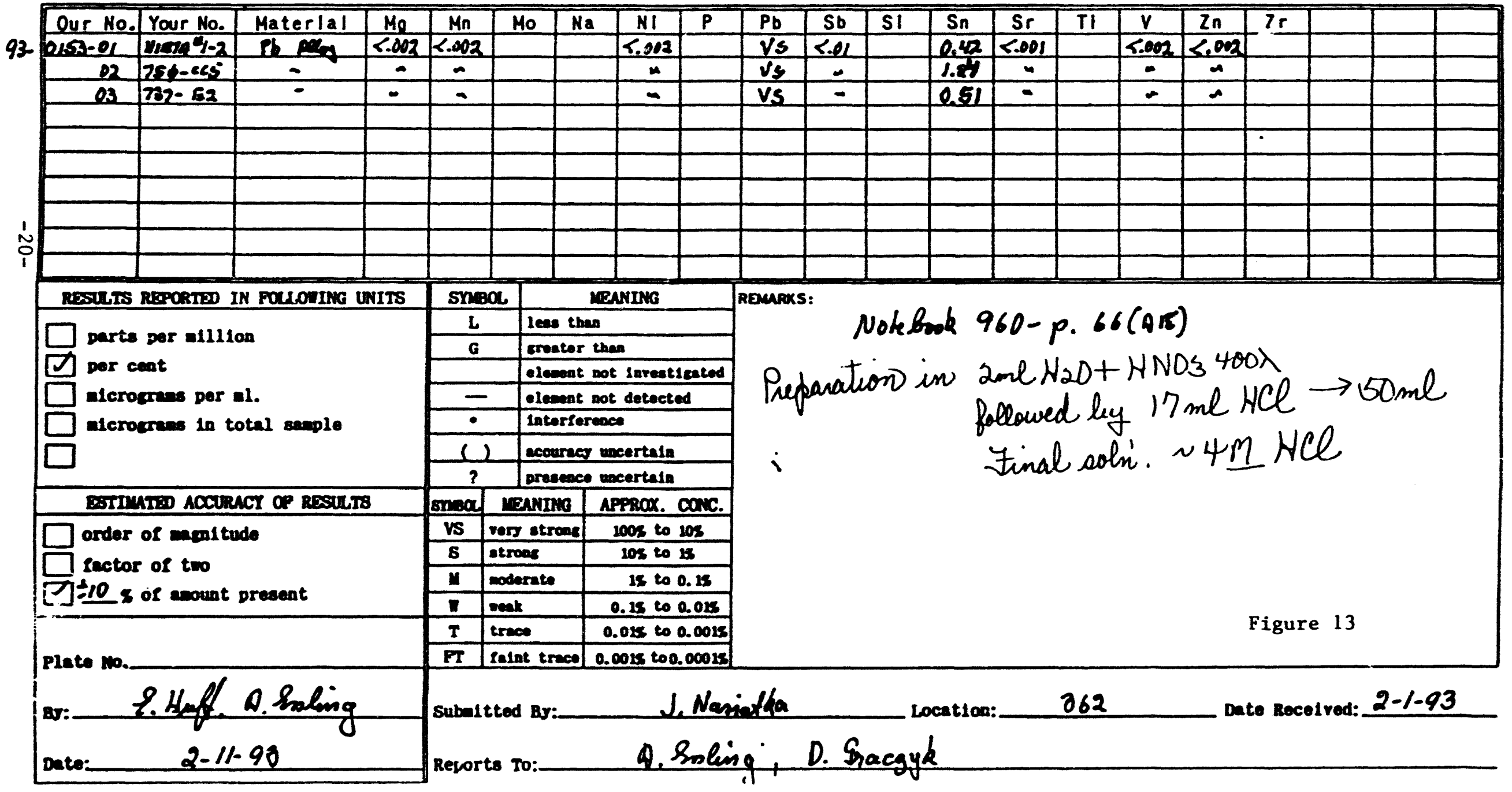




\section{Confirmation Analysis}

- Performed by ANL Analytical Chemistry

\begin{tabular}{|c|c|c|c|c|c|c|c|c|c|c|c|c|c|c|}
\hline Sample & Sn & Sb & $\mathrm{Cu}$ & As & Bi & Ag & $\mathrm{Ca}$ & $\mathbf{N}$ & AI & $\mathrm{Zn}$ & Cd & $\mathbf{s}$ & To & $\mathrm{Fe}$ \\
\hline \multirow[t]{2}{*}{ High Eta } & .52 &. .001 & .001 & -.001 & .01 & .001 & .06 & -.001 & .01 & -.001 & -001 & .0002 & -.001 & -.001 \\
\hline & .49 & -.05 & -.002 & -.05 & & & .059 & -.002 & -.02 & -.002 & -.002 & & & -.005 \\
\hline \multirow[t]{2}{*}{ L-50737 } & .51 & -.0005 & .0001 & -.0005 & .0097 & .0021 & .067 & .0001 &. .001 & .001 & & & & -.001 \\
\hline & .55 & -.05 & -.002 & .05 & & & .059 &. .002 & -.02 & -.002 & -.002 & & & -.005 \\
\hline \multirow[t]{2}{*}{$L-50750$} & 1.31 & -.0005 & .0001 & -.0005 & .0098 & .0038 & .066 & -.0001 & & -.001 & & & & .001 \\
\hline & 1.28 & -.05 & -.002 & -.05 & & & .050 & -.002 & .02 & .002 & -.002 & & & -.005 \\
\hline
\end{tabular}

Figure 14 


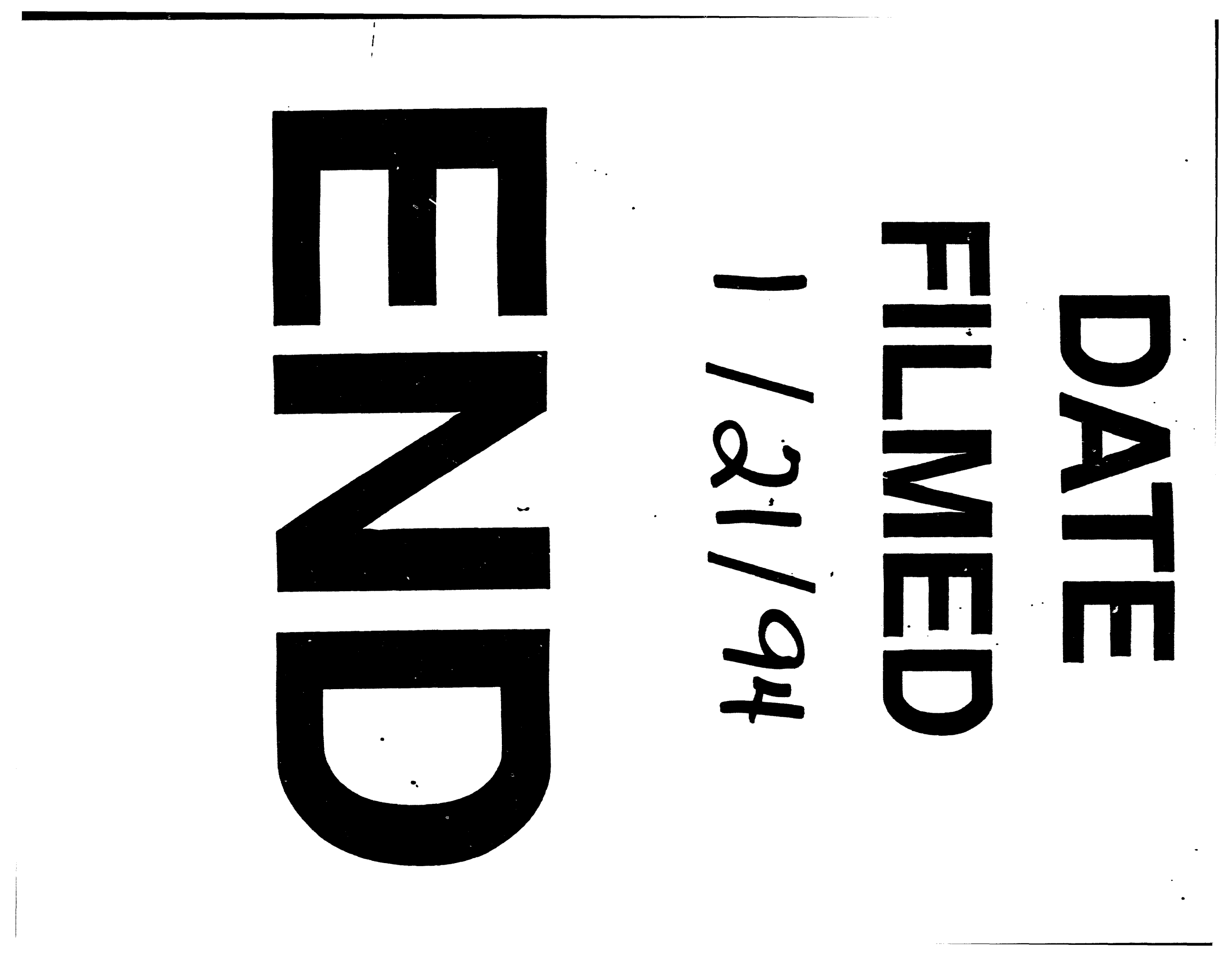


